\title{
Morphosynthesis of Hierarchical Hydrozincite with Tunable \\ Surface Architectures and Hollow Zinc Oxide
}

\author{
Chenglin Yan, Dongfeng Xue* \\ State Key Laboratory of Fine Chemicals, Department of Materials Science and \\ Chemical Engineering, School of Chemical Engineering, Dalian University of \\ Technology, 158 Zhongshan Road, Dalian 116012, P. R. China \\ *Corresponding author. E-mail: dfxue@chem.dlut.edu.cn
}

\section{Supporting Information}

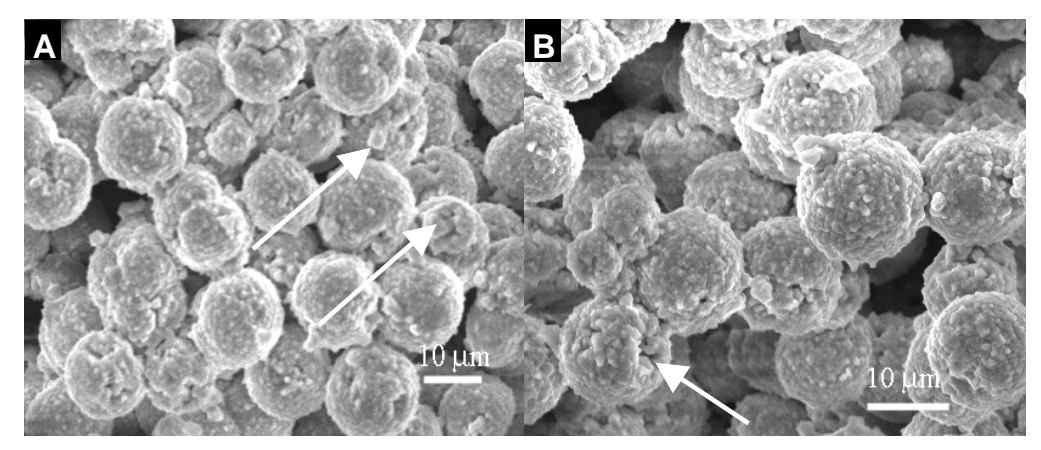

Figure S1. SEM images of the hierarchical $\mathrm{Zn}_{5}\left(\mathrm{CO}_{3}\right)_{2}(\mathrm{OH})_{6}$ microspheres.

Note: Many hierarchical microspheres can be seen in these images. The arrows show that some microspheres are not yet well assembled into well-shaped spheres, which make us believe that these microspheres are made of small nanocubes with a hierarchical structure. 


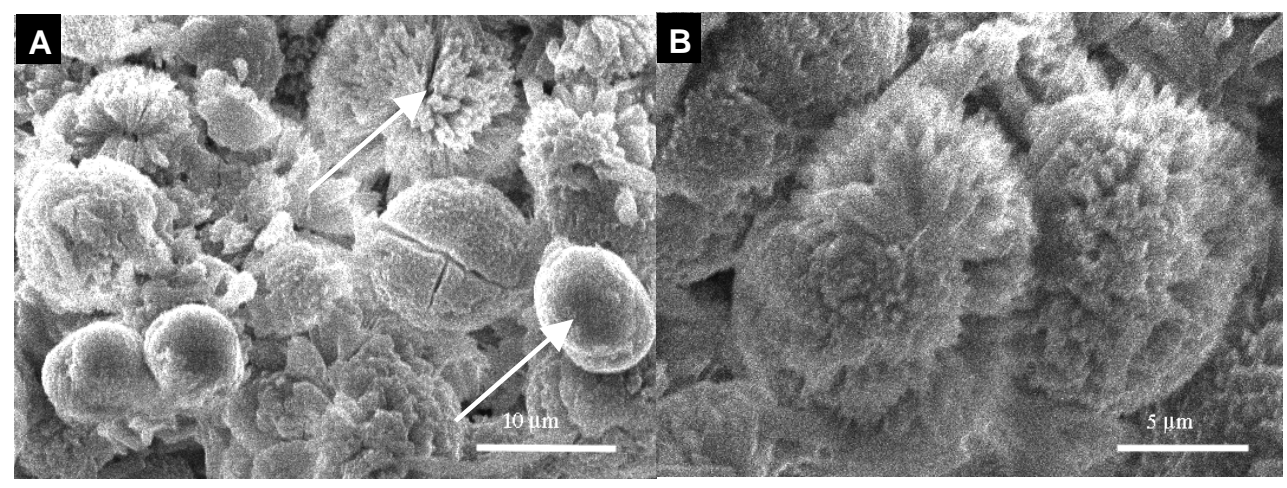

Figure S2. SEM images of $\mathrm{Zn}_{5}\left(\mathrm{CO}_{3}\right)_{2}(\mathrm{OH})_{6}$ microspheres with a reaction time of $2 \mathrm{~h}$. The smooth microspheres and nanorod-assembled microspheres coexist indicated by the arrows.

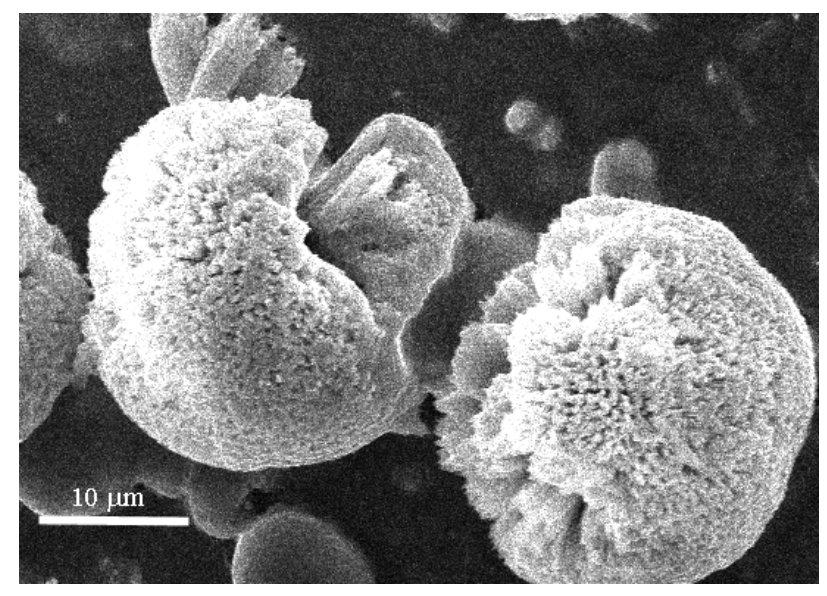

Figure S3. SEM image of $\mathrm{Zn}_{5}\left(\mathrm{CO}_{3}\right)_{2}(\mathrm{OH})_{6}$ microspheres with a reaction time of $3 \mathrm{~h}$. The nanorods becomes short with the increasing the reaction time. 


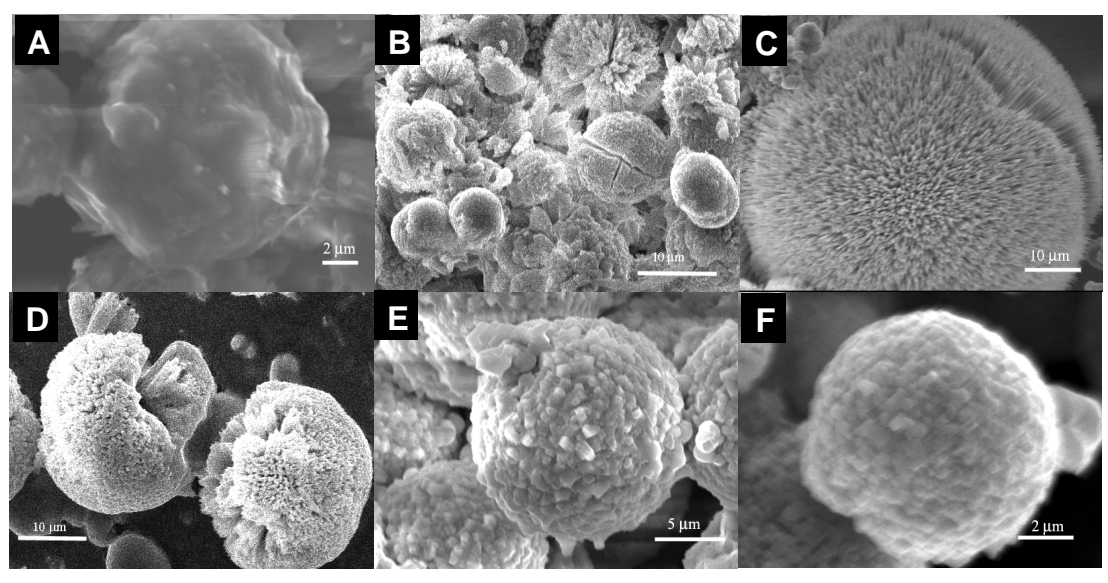

Figure S4. A summary of SEM images of $\mathrm{Zn}_{5}\left(\mathrm{CO}_{3}\right)_{2}(\mathrm{OH})_{6}$ microspheres at different reaction times: (A) 1.5h, (B) 2h, (C) 2.5h, (D) 3h, (E) 4h, (F) 5h.

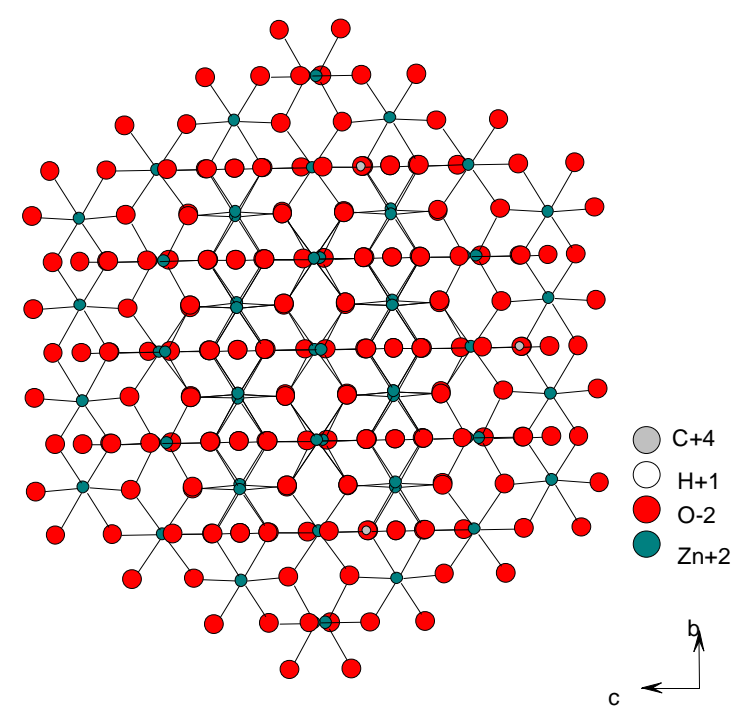

Figure S5. Projection of malachite structure along [100] direction, i.e. the (100) plane lies in the plane of the paper. 


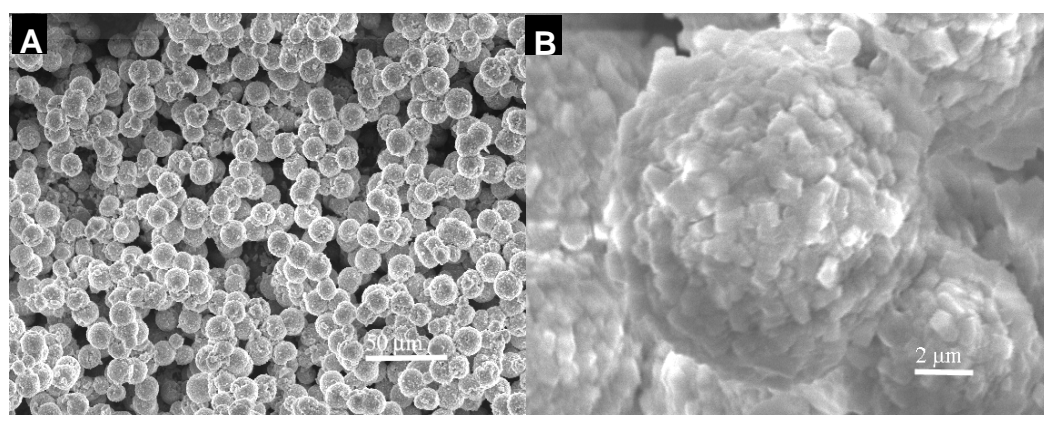

Figure S6. SEM images of the similar shape of filled $\mathrm{ZnO}$ microspheres obtained by calcination of $\mathrm{Zn}_{5}\left(\mathrm{CO}_{3}\right)_{2}(\mathrm{OH})_{6}$ microspheres at $450{ }^{\circ} \mathrm{C}$ in air: (A) Panoramic morphologies, (B) A detailed view on an individual $\mathrm{ZnO}$ microsphere. 